\title{
Influence of the domestic hot-water daily draw-off profile on the performance of a hot-water store
}

\author{
Roman Spur ${ }^{a}$, Dusan Fiala ${ }^{b, *}$, Dusan Nevrala ${ }^{c}$, \\ Doug Probert ${ }^{\mathrm{d}}$ \\ a Department of Environmental and Building Services, Faculty of Civil Engineering, \\ Czech Technical University in Prague, Czech Republic \\ b Institute of Energy and Sustainable Development, De Montfort University, Leicester LE1 9BH, UK \\ ${ }^{\mathrm{c}}$ Enplan - Heating Technology Company, Pod Vodovodem, Prague, Czech Republic \\ d School of Engineering, Cranfield University, Bedford MK 43 OAL, UK
}

Available online 7 October 2005

\begin{abstract}
An enhanced TRNSYS simulation model, NEM, of the behaviour of a domestic hot-water (DHW) store, with an immersed heat-exchanger (HX), has been developed and validated. This model simulates the dynamic heat-depletion and recovery processes in the immersed HX and predicts the transient temperature-patterns for various DHW draw-off versus time profiles. Realistic daily profiles (RDPs), based on field studies, were developed to provide representative draw-off patterns for the testing of thermal stores and simulation studies. The effects of these RDPs and five other existing profiles on the store's performance are analysed using the enhanced model. The simulation results indicate the importance of the HX's recovery, as well as the number, type and time of occurrence of the draw-offs in the profile, on the thermal store's performance. It is concluded that RDP profiles should be used in the performance testing of thermal stores to obtain results that reflect conditions experienced in the field.
\end{abstract} (C) 2005 Elsevier Ltd. All rights reserved.

Keywords: DHW store; Computer modelling; Immersed heat-exchanger; Draw-off profiles; Heat-recovery effects

\footnotetext{
* Corresponding author. Tel.: +44 0116257 7971; fax: +44 01162577981.

E-mail address: dfiala@dmu.ac.uk (D. Fiala).
}

0306-2619/\$ - see front matter (c) 2005 Elsevier Ltd. All rights reserved. doi:10.1016/j.apenergy.2005.07.001 


\section{Nomenclature and abbreviations}

BRE Building Research Establishment

C coefficient

DHW domestic hot-water

$d_{0} \quad$ external diameter of the HX's coil (m)

$E_{\mathrm{DHW}}$ power input to the domestic hot-water (W)

$E_{\text {unsup }}$ unsupplied energy to domestic hot-water (W)

EN European norm for extracted daily pattern of domestic hot-water drawoffs

EU European extracted domestic hot-water draw-off

HX heat exchanger

$h$ convection coefficient for heat exchanger $\left(\mathrm{W} / \mathrm{m}^{2} \mathrm{~K}\right)$

IEA International Energy Agency

$k \quad$ thermal conductivity $(\mathrm{W} / \mathrm{mK})$

$m \quad$ Exponent in the Nusselt number equation (2)

$m_{\mathrm{hx}} \quad$ mass-flow through heat exchanger $(\mathrm{kg} / \mathrm{s})$

NEM new enhanced-model of store

$\mathrm{Nu} \quad$ Nusselt number

$n \quad$ number

$R a \quad$ Rayleigh number of water

RDP Realistic daily profile

$T$ temperature $\left({ }^{\circ} \mathrm{C}\right)$

$T_{\text {bot }} \quad$ temperature at the bottom of the store $\left({ }^{\circ} \mathrm{C}\right)$

$T_{\mathrm{cw}} \quad$ inlet temperature of the heat-exchanger (i.e., of the cold water) $\left({ }^{\circ} \mathrm{C}\right)$

$T_{\text {DHWmin }}$ minimum temperature of the domestic hot-water $\left({ }^{\circ} \mathrm{C}\right)$

$T_{\text {hxbot }}$ temperature of lower part of the heat exchanger $\left({ }^{\circ} \mathrm{C}\right)$

$T_{\text {hxOut }}$ outlet temperature of the heat exchanger $\left({ }^{\circ} \mathrm{C}\right)$

$T_{\text {hxTop }}$ temperature of upper part of the heat exchanger $\left({ }^{\circ} \mathrm{C}\right)$

$T_{\text {top }}$ temperature at the top of the store $\left({ }^{\circ} \mathrm{C}\right)$

$\mathrm{UA}_{\mathrm{hx}}$ overall heat-transfer parameter for the heat exchanger $(\mathrm{W} / \mathrm{K})$

$V_{\text {DHW }}$ volume of domestic hot-water (1)

$\mathrm{V}_{\text {equi }}$ equivalent volume (1)

$V_{T 45-43}$ volume of domestic hot-water at temperatures from 45 to $43{ }^{\circ} \mathrm{C}$ (1)

$V_{T 43-40}$ volume of domestic hot-water at temperatures from 43 to $40{ }^{\circ} \mathrm{C}$ (1)

$V_{T<40}$ volume of domestic hot-water at temperatures below $40{ }^{\circ} \mathrm{C}$ (1)

$V_{\text {unsup }}$ unsupplied volume of domestic hot-water with temperatures below $45^{\circ} \mathrm{C}(1)$

$\Delta T \quad$ temperature difference $\left({ }^{\circ} \mathrm{C}\right)$

$\sigma \quad$ root mean square temperature deviation $\left({ }^{\circ} \mathrm{C}\right)$ 


\section{The problem}

There is a variety of designs of hot-water stores commercially available. It is difficult for most prospective purchasers to compare their performances and assess their efficiencies. Thus laboratory and simulation procedures, that enable the performance of thermal stores under conditions that correspond to those experienced in the field, are needed. Particular attention has to be paid to the designs of thermal stores featuring immersed HXs, as these occasionally fail to provide a satisfactory hot-water delivery (see Fig 1).

Various procedures have been used for the testing of domestic hot-water stores $[1,2]$ : these have employed different profiles of DHW usage. The profiles range from that for a continuous single draw-off discharge from the HX to a three draw-offs profile during a day [2], as well as profiles that attempt to simulate realistic usage [3]. However, most DHW profiles used are not based on experimental measurements arising from field studies.

One of the aims of the present study was to test the assumption that the DHW profile has a substantial influence on the perceived performance of the tested store. The basis for this assertion is that the daily use of DHW in residential buildings is characterised by several short-duration small-volume draw-offs, rather than by a few long extractions. The time elapsed between successive draw-offs is the "recovery" period, during which the temperature of the water in the HX should have sufficient time to rise substantially before the next demand occurs. In practice, this more realistic draw-off pattern should provide a better indication of the store's effectiveness than tests using a single or a limited number of draw-offs, all based on the assumption that the total volume of hot water withdrawn each day remains constant. Hence, new DHW extraction-profiles are proposed for use in laboratory testing and computer simulation behaviours of DHW stores.

\section{DHW storage}

Two basic types of store are used for the supply of DHW. The first utilises the water in the store to accumulate heat for delivery directly to members of the household; in the second, the DHW passes through a heat exchanger immersed in the

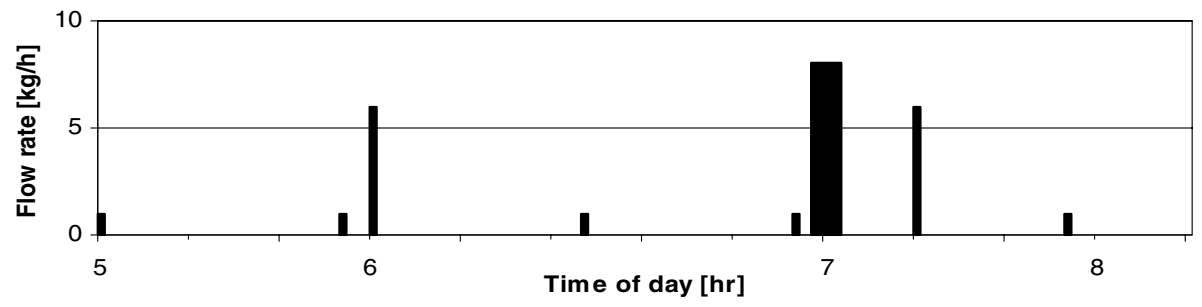

Fig. 1. DWH profile-plot for the rate of delivery of hot water versus time. 
hot-water store, which acts as its source of heat. The latter type is considered in this investigation. A standard vertical cylindrical store, with an immersed HX coil, which has its cold-water inlet near at the bottom and heated water emerging from its outlet near the top of tank was chosen - see Fig. 2. The basic design parameters are: store's volume $160 \mathrm{l}$, height $1 \mathrm{~m}$, internal diameter $0.45 \mathrm{~m}$, with an externally clad thermal insulation blanket of $4 \mathrm{~cm}$ thick polyurethane foam $(k=0.028 \mathrm{~W} / \mathrm{mK})$. The heated-water supply from the original heat-source (e.g., a gas flame) is connected to the top of the water store and the return from the tank occurs near its bottom. The inner helical HX is of copper pipe $22 \mathrm{~mm}$ external diameter, $37 \mathrm{~m}$ long and coiled as shown in Fig. 2. The volume of water in the HX is approximately 121.

\subsection{Storage-tank behaviour simulation-model}

The TRNSYS software [4] was used to model mathematically the temperature variations in the DHW store containing an immersed HX. TRNSYS offers a variety of "types" to simulate different behaviours of components of a DHW system. The most appropriate TRNSYS type, namely "Stratified-Fluid Storage Tank" type 60, which was chosen for the purposes of this study, is described in detail by Klein et al. [4]. This type enables the simulation of temperature stratification within the tank and incorporates a steady-state model of the behaviour of the immersed HX that takes into account temperature stratification in the tank. In the model, the overall heat-transfer parameter $\mathrm{UA}_{\mathrm{hx}}$ for the immersed $\mathrm{HX}$ is determined interactively. The outside convection coefficient $h_{0}$ is calculated using the following expression:

$$
h_{0}=\frac{N u}{d_{0}}
$$

where

$$
N u=C R a^{m},
$$

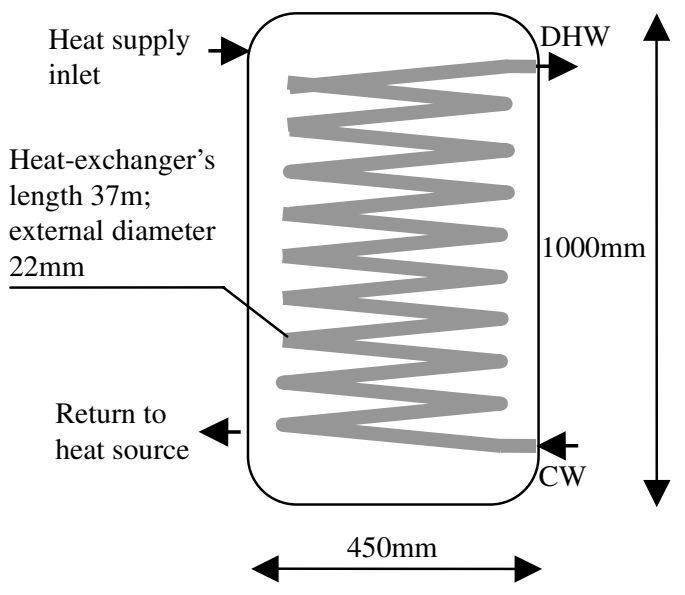

Fig. 2. Schematic of the considered system. 
$N u$ being the Nusselt number, $R a$ the Rayleigh number and $d_{0}$ the outside diameter of the HXs coil. The Nusselt number coefficient $C$ and exponent $m$ can be determined from measured data by means of a statistical regression-analysis. According to Holman [5], $m=0.25$ for laminar flow around the outside of the HX with values of $C$ ranging between 0.1 and 0.7 : if a value cannot be obtained from measurements for a particular configuration, a typical value $C=0.5$ is recommended [4]. Hence, in this study, this value of $C$ with $m=0.25$ was used to analyse the influence of the DHW profile on the system's performance.

\subsection{Effect of heat storage in the $H X$ (thereby enhancing the type 60 heat-storage model)}

The behaviour of the HX in the type 60 store is represented by a steady-state model that ignores the heat stored within volume of the water in the HX. However, the latter has to be taken into account to predict accurately the time-dependent DHW outlet temperature during (i) a short duration draw-off and (ii) at the beginning of an infrequent long draw-off when the whole volume of the HX can be at or near the store's adjacent temperature. It was therefore desirable to extend the steadystate HX behavioural model by considering the thermal mass of the water in the HX itself.

So the new enhanced model NEM of the DHW tank, with an immersed HX, takes into account the dynamics of heat storage in the water in the coiled pipe. The model combines (i) TRNSYS type 60 for calculating the behaviour of the DHW storage tank and the convective heat-exchange at the outer surface of the HX; and (ii) TRNSYS type 31 [4], which is a mathematical model simulating the heat-transfer and heat-storage effects within the HX. The HX is divided into three equal lengths, each length being modelled by TRNSYS type 60, connected to a TRNSYS pipe type 31 component. The schematic diagram of the enhanced model is shown in Fig. 3.

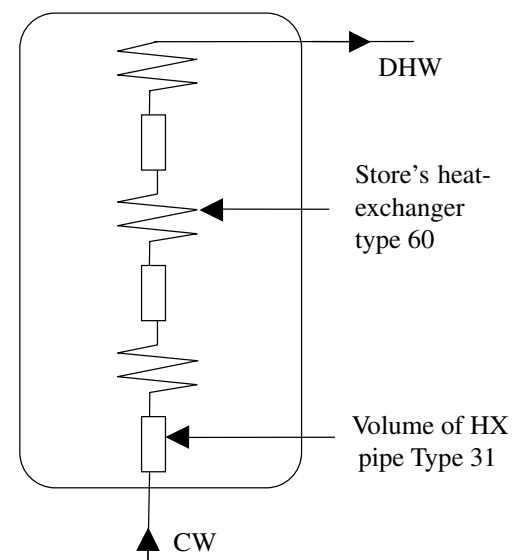

Fig. 3. Schematic of the enhanced model NEM. 
In order to determine the HXs outlet-temperature and the recovery behaviour with respect to the store's temperature distribution, simulations for the same initial conditions were carried out using the TRNSYS type 60 and the enhanced NEM models, as described previously. The store is initially charged to a temperature of $80{ }^{\circ} \mathrm{C}$ and, during the entire simulation, a flow rate through the $\mathrm{HX}$ of $10 \mathrm{l} / \mathrm{min}$ and an inlet temperature of $10^{\circ} \mathrm{C}$ are maintained. The resulting outlet temperature ( $\left.T_{\text {hxOut }}\right)$ of the HX, as well as the temperatures at the top ( $\left.T_{\text {top }}\right)$ and the bottom ( $T_{\text {bot }}$ ) of the store for the NEM and type 60 store models are shown in Fig. 4. The draw-off temperature profile can be divided into three phases, namely $\mathrm{a}, \mathrm{b}$ and $\mathrm{c}$. Phase a is characterised by the withdrawal of 121 of water from the HX in approximately $70 \mathrm{~s}$. For the NEM, the HXs outlet temperature by definition has to be the same (i.e., $80^{\circ} \mathrm{C}$ ) as the temperature at the top of the store: the temperature of the store's bottom starts to drop with a delay due to the relatively low heat conductivity of the water. However, for the original store type 60 , the initial temperature of the flow from the $\mathrm{HX}$ outlet is $75^{\circ} \mathrm{C}$ and the temperatures at the top and bottom of the store start dropping immediately. Phase b shows a rapid decrease in the temperature of the water flowing out from the HX for the enhanced model until stable conditions within the HX are attained: also the top-store temperature begins to decrease moderately quickly. This does not occur for the type 60 simulated temperatures. Phase $\mathrm{c}$ of the simulation occurs when a steady-state heat transfer ensues. Therefore, the curves of the DHW outlet temperature predicted by the original model, of the type 60 store, and the NEM are approximately parallel in Fig. 4. The time elapsed from the beginning of the simulation until a steady state is attained explains the higher temperatures of the withdrawn water for the NEM.

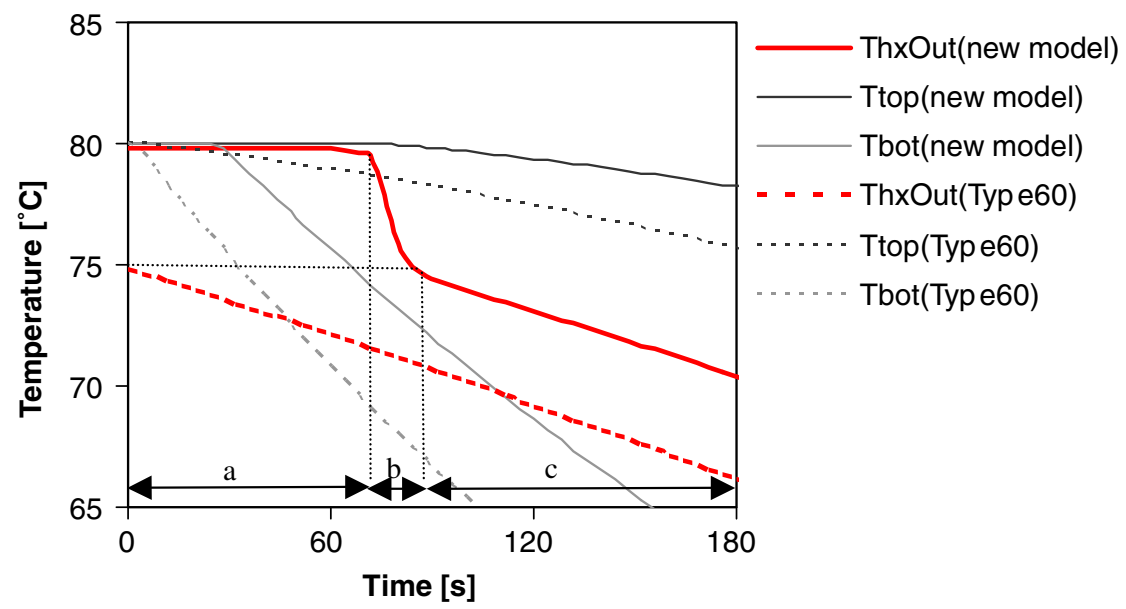

Fig. 4. Store temperatures for standard TRNSYS (type 60) and the enhanced NEM simulating the HXs behaviour. Initial store-temperature $=80^{\circ} \mathrm{C}, \mathrm{HX}$ 's flow rate $=101 / \mathrm{min}$, temperature of cold water entering the $\mathrm{HX}=10^{\circ} \mathrm{C}$. Outlet temperature of the $\mathrm{HX}\left(T_{\text {hxOut }}\right)$, and temperatures at the top $\left(T_{\text {top }}\right)$ and bottom ( $\left.T_{\text {bot }}\right)$ of the store. 


\subsection{Model validation}

Once the NEM-enhanced TRNSYS model was developed, the next step was a comparison of the predicted with the measured data obtained from Enplan [6] for a complex HX arrangement - see Fig. 5(a) and 5(b). At the beginning of the experiments, the store was charged to $85^{\circ} \mathrm{C}$. Initially, there was no temperature stratification in the tank. The measured temperatures at the top ( $\left.T_{\text {top }}\right)$ and bottom $\left(T_{\text {bot }}\right)$ of the store, at the inlet $\left(T_{\mathrm{cw}}\right)$ and the outlet $\left(T_{\mathrm{hxOut}}\right)$ of the HX as well as the mass flow $\left(m_{\mathrm{hx}}\right)$ through the HX were subsequently recorded at $2 \mathrm{~s}$ intervals. A thermostatic mixing-valve was adjusted to obtain the chosen temperature of the DHW. Two measurements, for different flow-rates, were undertaken: Fig. 5(a) is for the "low" HX flow-rate and Fig. 5(b) for the "high" HX flow-rate. As can be seen in Fig. 5(a), there was a delay of about $60 \mathrm{~s}$ in the water temperature $\left(T_{\mathrm{bot}}\right)$ drop at the bottom of the store. The delay in the temperature drop $\left(T_{\mathrm{hxOut}}\right)$ at the HX outlet was about $120 \mathrm{~s}$. Simultaneously the water temperature $\left(T_{\text {top }}\right)$ at the top of the store started visibly to fall. The new enhanced TRNSYS model represented this dynamic behaviour well. The temperature characteristics of the second comparison in Fig. 5(b) are similar qualitatively.
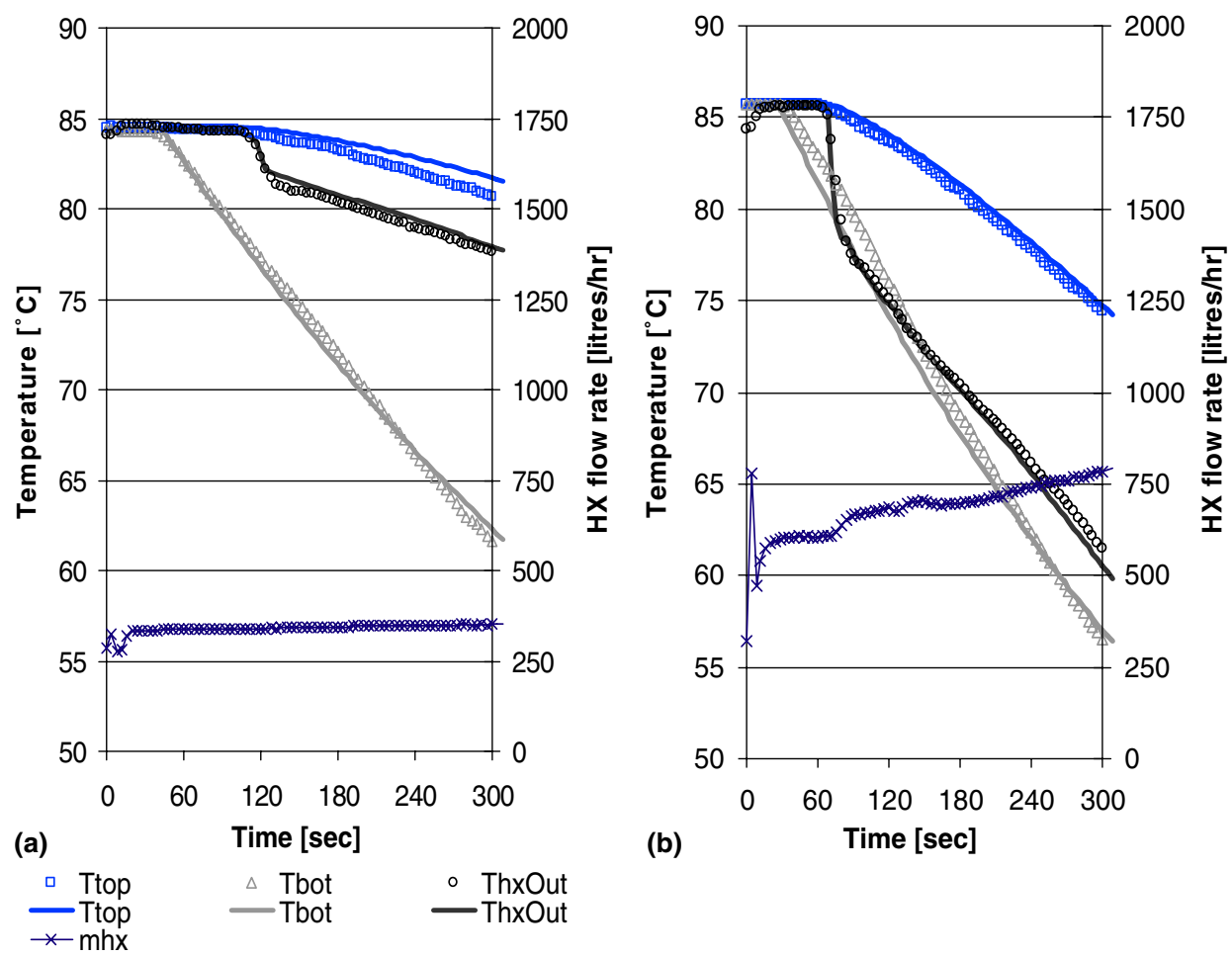

Fig. 5. Comparison of the measured and predicted temperatures at the top and bottom of the store, and at the outlet of the $\mathrm{HX}\left(T_{\mathrm{hxOut}}\right)$. Temperature $\left(T_{\mathrm{cw}}\right)$ of the cold water $=7.5^{\circ} \mathrm{C}$. 
There was good agreement between the experiment and its simulation. The temperature differences are expressed by the mean square deviation

$$
\sigma=\sqrt{\sum_{i}^{n} \frac{\Delta T^{2}}{n}} .
$$

For the "low" $\mathrm{HX}$ flow-rate, $\sigma_{\text {Ttop }}=0.71{ }^{\circ} \mathrm{C}$ at the top and $\sigma_{\text {Tbot }}=0.59{ }^{\circ} \mathrm{C}$ at the bottom of the store, and $\sigma_{\text {ThxOut }}=0.35^{\circ} \mathrm{C}$ at the outlet of the HX. For the "high" $\mathrm{HX}$ flow-rate, the differences are $\sigma_{\mathrm{Ttop}}=0.33{ }^{\circ} \mathrm{C}$ at the top, $\sigma_{\mathrm{Tbot}}=1.13{ }^{\circ} \mathrm{C}$ at the bottom of the store and $\sigma_{\text {ThxOut }}=0.73{ }^{\circ} \mathrm{C}$ for outlet of the HX.

\section{Existing DHW profiles}

The DHW daily-consumption as well as the consumption pattern with time vary from household to household [7]. In practice, it is therefore difficult to define representative DHW-demand profiles. So several DHW profiles are in common use, each with a different withdrawal-temperature pattern, flow rate and time schedule of draw-offs in the course of a day.

For instance, EN 12977 [2] proposed a reference DHW withdrawal profile for the simulation of the behaviour of solar-heated domestic-hot-water systems (SDHW). This profile consists of three draw-offs in the course of a day (namely at $7 \mathrm{am}$, noon and $5 \mathrm{pm}$, the corresponding withdrawals being in proportions of the total daily extraction of $2 / 5,1 / 5$ and $2 / 5$, respectively) with a constant flow-rate of $101 / \mathrm{min}$. A temperature $T_{\mathrm{DHW}}=45^{\circ} \mathrm{C}$ for the emergent DHW is assumed and the cold-water temperature $T_{\mathrm{cw}}=10^{\circ} \mathrm{C}$.

For system testing and the comparison of performance, the BRE (Building Research Establishment) laboratories use their own profiles. These are classified as "light", "medium" and "heavy", according to the flow-rate and total volume of the extracted DHW. Nine draw-off periods are spread, from 7:15 am to 21:30 pm, throughout the day. The temperature difference $\Delta T$ between the hot and cold water is assumed to be $55^{\circ} \mathrm{C}$ and the total volumes are for BRE1 1681 , for BRE2 2981 and for BRE3 3831.

CEN and CENELEC [8] suggest three extraction-cycles, which were developed for the European measurement standards of DHW-storage appliances. These tapping patterns apply to a variety of commonly used water-heating appliances and storage vessels that are sold in the European market. The daily patterns are:

- EU1, 11 draw-offs, with an energy equivalent of 361 at $60{ }^{\circ} \mathrm{C}$ (including one modest shower in the evening);

- EU2, 23 draw-offs, with an energy equivalent of 1001 at $60{ }^{\circ} \mathrm{C}$ (including two showers);

- EU3, 24 draw-offs, with an energy equivalent of 2001 at $60^{\circ} \mathrm{C}$ (including two baths and one shower). 
All draw-offs of the tapping cycle (e.g., for dishwashing, showering or bathing) are categorised according to flow rate and desired temperature-difference between the cold water $\left(T_{\mathrm{cw}}=10^{\circ} \mathrm{C}\right)$ and hot water. Dishwashing is assumed to be characterised by three different loads (small: 61 ; medium: 81 ; and large: $14 \mathrm{l}$; all at $\Delta T=45^{\circ} \mathrm{C}$ ), whereas each shower consumes 401 and a bath 1031 , both at $\Delta T=30^{\circ} \mathrm{C}$.

In recent years, several field studies of DHW consumption-patterns have been carried out in European countries [9-12]. These focused on the measurements of flowrate and the temperature of the DHW. The collected data were evaluated statistically and formed the basis for developing a mathematical model for the prediction of realistic whole-year load profiles for DHW [7]. This Jordan and Vajen model simulated the behaviour of a solar combisystem in Task 26-IEA [13]: it considered daily, weekly, annual and holiday probabilities of draw-off occurrences; and was used to generate whole-year flow-rate data for hot-water demands of 100, 200, 400, 800 1/ day, in time intervals between $1 \mathrm{~h}$, down to $1 \mathrm{~min}$.

Thus there is a wide diversity of DHW profiles for test and simulation purposes, with a range of volume, duration and flow rate of draw-offs being used. However, none of these profiles entirely suits the purposes of this study. For instance, the Jordan and Vajen model [7], based on field measurements, can reproduce a DHW profile in a household for each day of a whole year. However, the testing of stores over a period of a whole year, under laboratory conditions would be highly expensive and so not feasible. A more cost effective way of testing DHW stores would be to employ a daily profile that best represents the usage of DHW based on a statistical analysis of a whole-year's data. In this investigation, such profiles are proposed and developed, and their effects on the DHW store's performance analysed.

\subsection{Development of daily DHW draw-off profiles based on measured data}

For an evaluation of the performance of a hot-water store, it is necessary to use draw-off schedules representing a mean DHW profile for that particular household. In response, realistic daily profiles (RDPs), based on average daily DHW draw-off profiles corresponding to realistic user behaviour, were evolved.

In the development of RDP profiles, recently conducted, statistically analysed field measurements, research studies and contemporary trends in Europe were utilised. Basic considerations in the development of a RDP are as follows.

\subsubsection{Different thermal loads and frequencies of draw-off occurrences}

The basis for developing the mean daily-profiles was the processed statistical data of DHW draw-offs from field measurements provided by Jordan and Vajen [7]. The statistical data of Jordan's model represent the average daily number, duration, flow rates and probabilities of four different loads (short, medium, shower and bath) for a daily DHW consumption of 2001 and are listed in Table 1.

Jordan's model also provides the probability of occurrence for each load, statistically derived from measurements in the course of a day. While short and medium 
Table 1

Draw-off data for the assumed daily DHW consumption of 2001 at $45^{\circ} \mathrm{C}[7]$

\begin{tabular}{lcccc}
\hline & Short & Medium & Shower & Bath \\
\hline Flow rate (l/min) & 1 & 6 & 8 & 14 \\
Duration (min) & 1 & 1 & 5 & 10 \\
Occurrences per day & 28 & 12 & 2 & 0.143 \\
Volume of load (1) & 1 & 6 & 40 & 140 \\
Volume per day (1) & 28 & 72 & 80 & 20 \\
Proportion of total volume & 0.14 & 0.36 & 0.40 & 0.1 \\
Water energy content $(\mathrm{kWh})$ & 1.14 & 2.93 & 3.26 & 0.81 \\
\hline
\end{tabular}

loads are relatively uniformly spread from 5 am to $11 \mathrm{pm}$, the use of showers has the highest probability around $7 \mathrm{am}$, being slightly lower near 7:30 pm and a bath is usually taken in the evening around $7 \mathrm{pm}$. The probability of any draw-off from $11 \mathrm{pm}$ to $5 \mathrm{am}$ is low.

\subsubsection{Water temperatures}

In the past, the commonly used DHW temperature was around $55^{\circ} \mathrm{C}$. So, high heat-losses from the pipe between the store and the tap were one of the factors causing a significant decrease in the DHW's temperature. Applications involving lowtemperature alternative sources of energy have resulted in the general acceptance of $45^{\circ} \mathrm{C}$ as the adopted DHW temperature.

Also the temperature of cold water varies commonly between 5 and $15{ }^{\circ} \mathrm{C}$, depending on the time of year and location. In common practice, the temperature of cold water is assumed to be $10^{\circ} \mathrm{C}$.

Therefore, for the RDP, the temperature of the DHW is assumed to be $45^{\circ} \mathrm{C}$ and that of the cold water $10^{\circ} \mathrm{C}$.

\subsubsection{Volume of $\mathrm{DHW}$}

Jordan's model was evolved for a daily consumption of 2001 . However, it is desirable to consider average daily DHW consumptions that represent specific categories of usage. According to the SAVE-4 study [14], the equivalent daily hot-water consumption of an average European citizen is 361 (corresponding to $2.09 \mathrm{kWh}$ ), assuming the temperature of the hot water is $60{ }^{\circ} \mathrm{C}$ and that of the cold water $10{ }^{\circ} \mathrm{C}$. According to DIN 4708 [15], a standard household comprises a four-room apartment and is occupied by 3.5 persons. Therefore, the average daily hot-water consumption of that standard household necessitates the expenditure $7.32 \mathrm{kWh}$ and this corresponds to 1801 of water being heated through a temperature differential $\Delta T$ of $35^{\circ} \mathrm{C}$.

In order to cover the wide scale of DHW usages in households, it was decided to propose, for assessment purposes in the market place, three RDP test profiles, based on the same duration and flow rates of thermal loads. A daily low-consumption (100 1) profile (RDP1) represents that for a two-person household, the standardconsumption (1801) profile (RDP2) that for the standard 3.5 person household 
and the high-consumption (3201) profile (RDP3) that for a 3.5 person household, but with a high DHW consumption.

For each profile, the number of baths and showers taken daily were chosen and then, as per Jordan's model, the number of small and medium loads was calculated by proportioning to achieve the profile volume. Draw-offs from $11 \mathrm{pm}$ to 5 am were excluded from the profile because of their low probabilities of occurrence.

\subsection{Light realistic daily-profile - RDP1 (see Fig. 6)}

For this, the shower is used only once in the morning, a bath is excluded and the number of short and medium loads is deduced proportionally from that of the standard profile. The energy consumption is $4.07 \mathrm{kWh}$ (see Table 2).

\subsection{Medium realistic daily profile - RDP2 (see Fig. 7)}

This represents the average DHW profile of a European household: the total calculated quantity of DHW daily withdrawal is 180 , with two showers, but no bath, being taken. The first shower is scheduled to occur at 7 am and second at 7:30 pm and short loads and medium draw-offs being taken from 5 am to $11 \mathrm{pm}$. The energy equivalent of the demand is $7.33 \mathrm{kWh}$ (see Table 3 ).

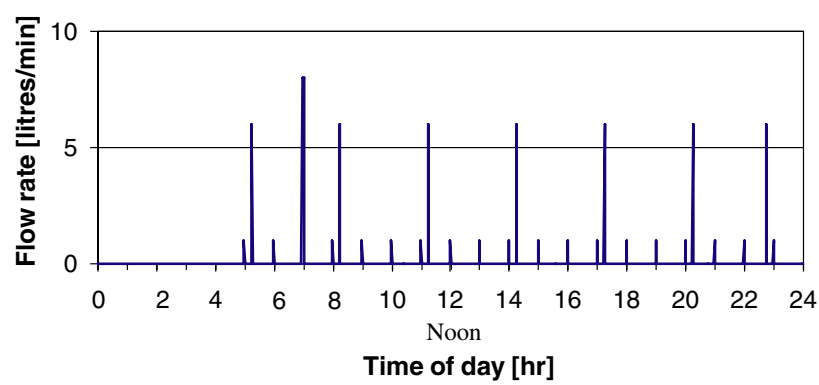

Fig. 6. "Light-load profile" RDP1: flow rates and occurrences of draw-offs during the day.

Table 2

RDP1 parameters

\begin{tabular}{lcccc}
\hline & Short & Medium & Bath & Shower \\
\hline Flow rate (1/min) & 1 & 6 & n/a & 8 \\
Duration (min) & 1 & 1 & n/a & 5 \\
Occurrences per day & 18 & 7 & n/a & 1 \\
Volume of load (1) & 1 & 6 & n/a & 40 \\
Volume per day (1) & 18 & 42 & n/a & 40 \\
Proportion of total volume & 0.18 & 0.42 & n/a & 0.40 \\
\hline
\end{tabular}

"Light" DHW profile 100 1/day. 


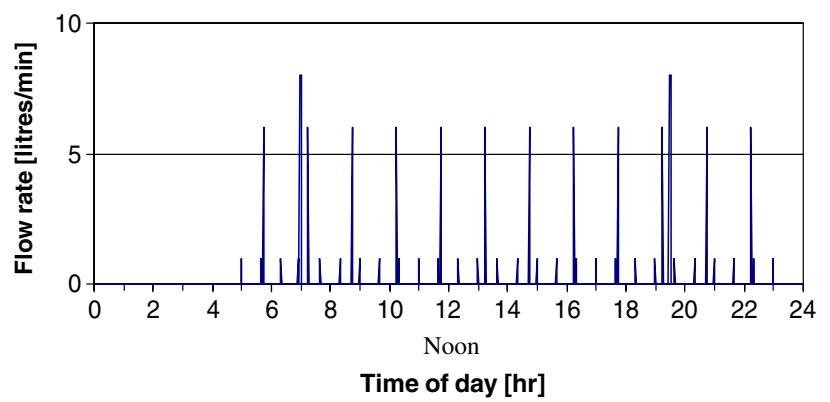

Fig. 7. "Medium-load" profile RDP2: flow rates and occurrences of draw-offs during the day.

Table 3

RDP2 parameters

\begin{tabular}{lcclc}
\hline & Short & Medium & Bath & Shower \\
\hline Flow rate (1/min) & 1 & 6 & n/a & 8 \\
Duration (min) & 1 & 1 & n/a & 5 \\
Occurrences per day & 28 & 12 & n/a & 2 \\
Volume of load (1) & 1 & 6 & n/a & 40 \\
Volume per day (l) & 28 & 72 & n/a & 80 \\
Proportion of total volume & 0.16 & 0.40 & n/a & 0.44 \\
\hline
\end{tabular}

"Medium" DHW profile 180 1/day.

\section{4. "Heavy" realistic daily profile - RDP3 (see Fig. 8)}

This is for a high water-consumption household and includes one bath at $7 \mathrm{pm}$ and two showers namely at $7 \mathrm{am}$ and 7:30 am. Short and medium loads are the same as for the medium profile. The total volume of DHW draw-offs is 3201 , with an equivalent energy expenditure of $13.03 \mathrm{kWh}$ (see Table 4).

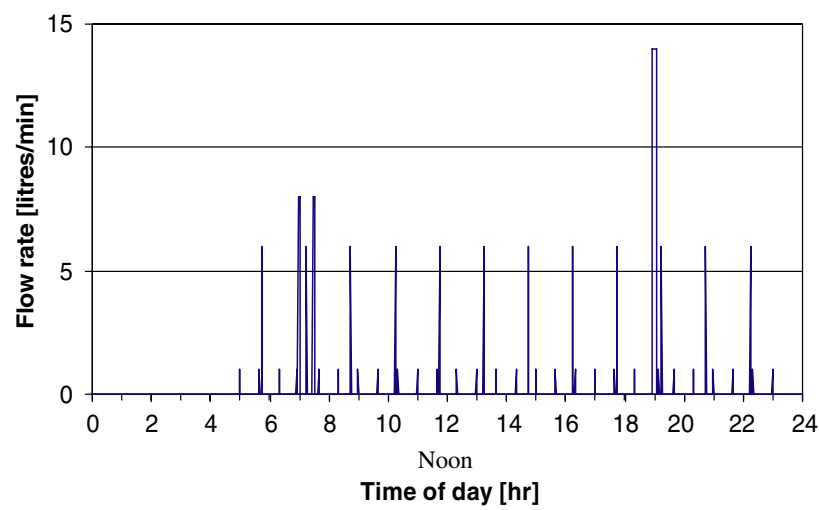

Fig. 8. "High-demand" load profile RDP3: flow rates and occurrences of draw-offs during the day. 
Table 4

RDP3 parameters

\begin{tabular}{|c|c|c|c|c|}
\hline & Short & Medium & Bath & Shower \\
\hline Flow rate (1/min) & 1 & 6 & 14 & 8 \\
\hline Duration (min) & 1 & 1 & 10 & 5 \\
\hline Occurrences per day & 28 & 12 & 1 & 2 \\
\hline Volume of load (1) & 1 & 6 & 140 & 40 \\
\hline Volume per day (l) & 28 & 72 & 140 & 80 \\
\hline Proportion of total volume & 0.09 & 0.23 & 0.44 & 0.25 \\
\hline
\end{tabular}

"Heavy" DHW profile 320 1/day.

\section{Simulation of DHW storage using different daily draw-off profiles}

An objective of this study was to analyze the effects of different draw-off profiles on the performance of DHW stores using the TRNSYS simulation. In practice, every DHW storage system operates under specific stimulations and conditions, such as different heat-sources, positions of the store's thermostat sensors and set controltemperatures. In order to avoid confusion and misleading results due to the various systems, it became apparent that a testing and simulation protocol for DHW storage systems, based on precisely defined testing-conditions and procedure, had to be specified. The resulting test process, i.e., the outcome of this investigation, was designed to replicate the usage pattern of the DHW store when the store is charged to a specified temperature by a heat source, then discharged in the course of the day by a sequence selected from several different draw-off patterns and, after being depleted, the store being thermally recharged.

The proposed test conditions assume an initially charged store at $80{ }^{\circ} \mathrm{C}$ with no additional energy being added during the test. Testing can be carried out with, or without, a thermostatic mixing-valve set at $T_{\mathrm{dhw}}=45^{\circ} \mathrm{C}$ and the temperature $T_{\mathrm{cw}}$ of the inlet cold water is considered to be $10{ }^{\circ} \mathrm{C}$.

A comparison of six different profiles was carried out over a day, in order to examine the effect of the number of draw-offs on the store's performance. For this comparison, the RDP2 profile (42 draw-offs), EU2 profile (24 draw-offs) [8] BRE1 profile (8 draw-offs) and EN 12977 profile (3 draw-offs) [2] were chosen. Additionally, as a benchmark, the frequently-used laboratory test of a single draw-off was added. The draw-off profile was run at both at the beginning of the day and at noon in order to explore the influence of the time of draw-off on the store's performance. To enable a valid comparison of different profiles, the volume of RDP2 (i.e., 1801 of hot water) was chosen as the reference volume. The total volume involved in the EU2mod (modified) and BRE1mod draw-offs was adjusted to 1801 with each separate draw-off proportionally increased. All profiles are shown in Fig. 9.

\subsection{Simulation of store behaviours}

The set of simulations was carried out using the thermal store described in Section 2.2 connected to a thermostatic mixing-valve, as is usually installed in practice. The 

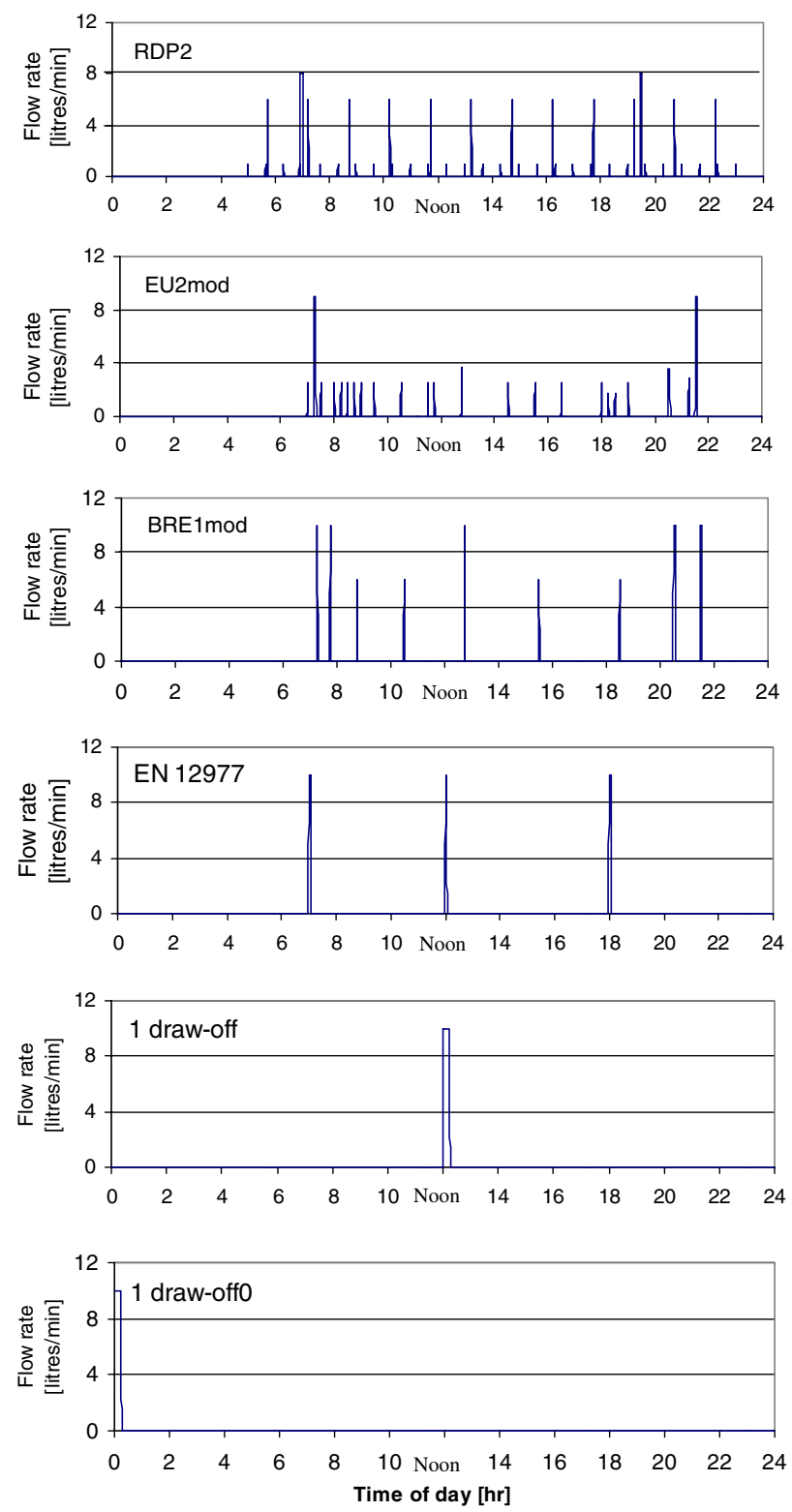

Fig. 9. Flow rates and occurrences of draw-offs for six DHW profiles - RDP2, EU2mod [8], BRE1mod, EN 12977 [2] and single draw-off with starts at noon (1 draw-off) and beginning of a day (1 draw-off0). Total water-volume of each profile is 1801 .

valve merges the heated water from the $\mathrm{HX}$ with cold water, at $10^{\circ} \mathrm{C}$, from the mains to achieve the desired DHW temperature of $45^{\circ} \mathrm{C}$. The predicted temperatures in the store and HX for each profile are plotted in Fig. 10. However, some 

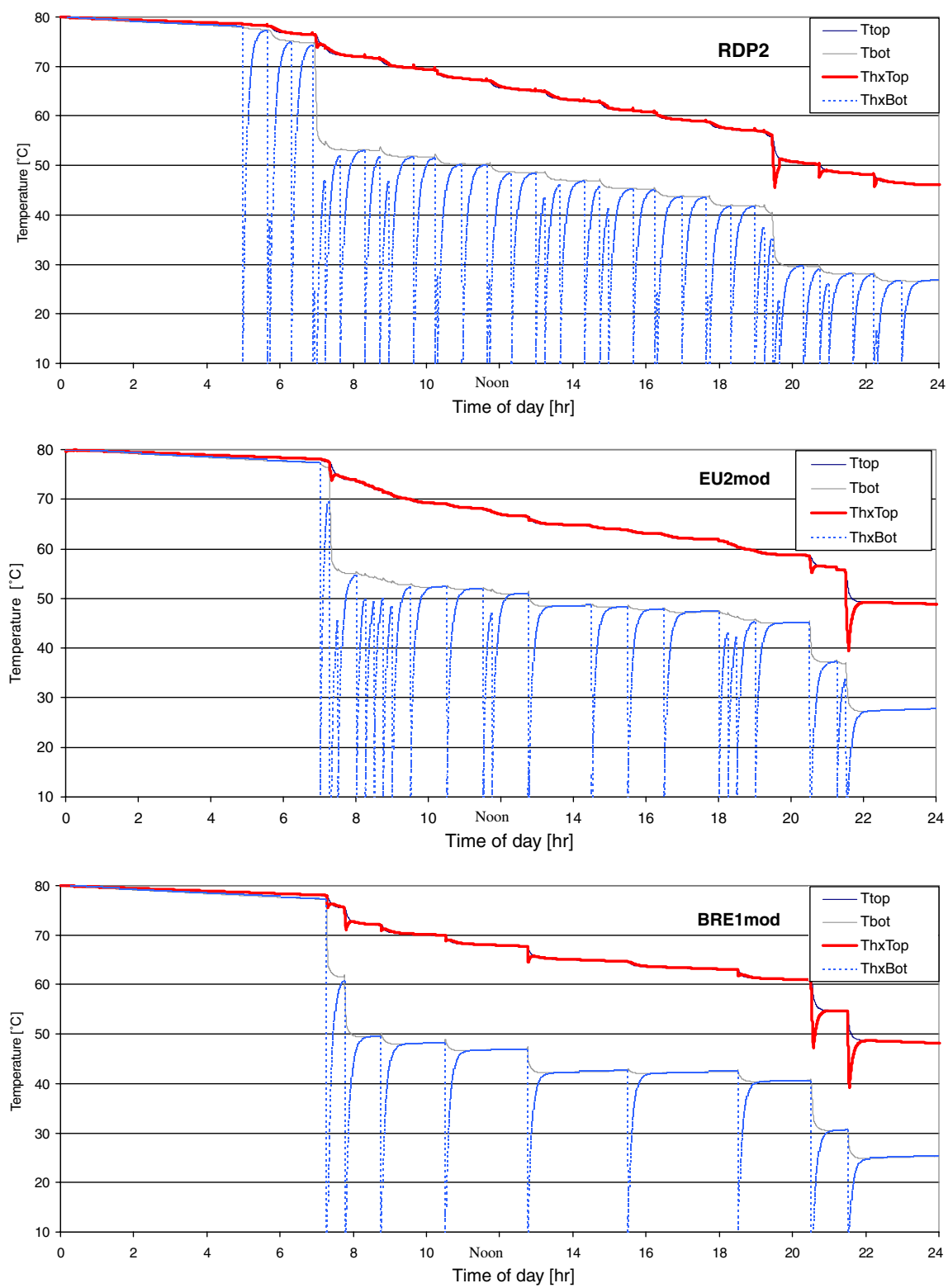

Fig. 10. Simulated temperatures in the store and the heat exchanger for RDP2, EU2mod, BRE1mod, EN 12977, 1 draw-off and 1 draw-off0 during a day. Store $=1601$, with thermostatic mixing-valve. Temperatures at the top $\left(T_{\text {top }}\right)$ and bottom $\left(T_{\text {bot }}\right)$ of store and the temperature of heat exchanger at upper $\left(T_{\mathrm{hxTop}}\right)$ and lower regions $\left(T_{\mathrm{hxBot}}\right)$.

laboratory tests of stores are conducted without a thermostatic mixing-valve in order to avoid having to evaluate the behaviour of the store and valve as a two-component system. Therefore simulations were also carried out without a thermostatic 

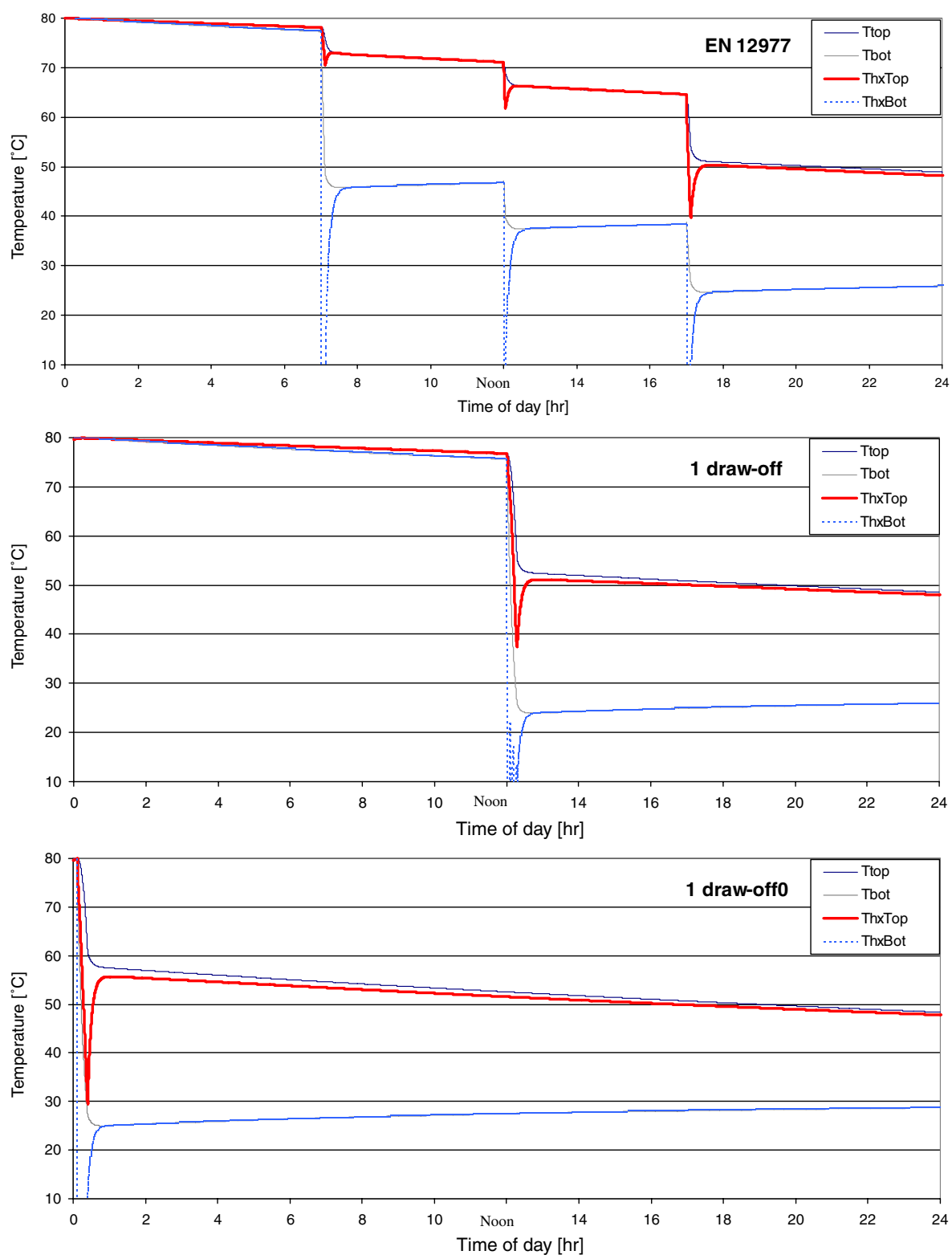

Fig. 10 (continued)

mixing-valve. Because the simulation characteristics of the same profile, with and without, a thermostatic mixing-valve, are similar, profile simulation results without a thermostatic mixing-valve are not provided.

The temperatures at the top $\left(T_{\text {top }}\right)$ and the bottom $\left(T_{\mathrm{bot}}\right)$ of the store as well as the temperatures at the bottom $\left(T_{\mathrm{hxBot}}\right)$ and the top $\left(T_{\mathrm{hxTop}}\right)$ of the HX for six different 
draw-offs profiles, namely RDP2, EU2mod, BRE1mod, EN 12977, 1 draw-off and 1 draw-offo, are plotted in Fig. 10. The store was initially charged to $80{ }^{\circ} \mathrm{C}$. While the temperature $T_{\text {hxTop }}$ drops only slightly for short and medium draw-offs for the RDP2 and EU2 profiles, for long draw-offs, the flow temperature decreases more noticeably. The highest temperature decrease occurs when the store temperature is low and a prolonged high flow-rate draw-off is made.

\subsection{Effects of temperature recovery in the $H X$ and number of draw-offs}

During each draw-off, the temperature in the HX pipe drops from that of the adjacent stored water. This difference depends on the length of the HXs pipe, the duration of the draw-off, the flow rate through the HX, the temperatures of the cold and hot water, the storage temperature and also on the location of the HX within the store. Once the draw-off is stopped, the temperature in the HX begins to rise and, if sufficient time is allowed, it reaches the temperature of the surrounding stored water. The enhanced store model NEM predicts the temperature-recovery effect in the HX, which is important for the precise simulation of each draw-off of the profile. The effects of temperature recovery in the HX and the DHW store's temperature for each profile can be seen in Fig. 10. The temperature $\left(T_{\mathrm{hxBot}}\right)$ at the bottom of the HX drops after the start of the draw-off due to cold water entering the HX. When the flow through the HX is stopped, its temperature starts to rise and eventually reaches the same temperature as the adjacent region in the store. The temperature $\left(T_{\mathrm{hxTop}}\right)$ at the top of HX is not affected significantly by short and medium draw-offs, as the water originally within the HX is far from entirely withdrawn. A significant temperature-drop only ensues for long draw-offs. Then the temperature-recovery effect is initiated and the temperature in the HX reaches the temperature at the corresponding upper level in the store. Generally, the HXs recovery takes about 20 min depending on the temperature difference and the HXs heat-transfer coefficient.

\section{Analysis simulation results}

\subsection{Analysis of the behaviour of the system with a thermostatic mixing-valve}

The main simulation results for each profile are summarised in Table 5. These include the withdrawal volume ( $\left.V_{\mathrm{DHW}}\right)$ and the consumed energy for the DHW $\left(E_{\mathrm{DHW}}\right)$, "unsupplied" energies required for the DHW to reach $45^{\circ} \mathrm{C}\left(E_{\text {unsup }}\right)$ and for the total volume of DHW below $45^{\circ} \mathrm{C}$ ( $\left.V_{\text {unsup }}\right)$, ratios of unsupplied and supplied energies $\left(E_{\text {unsup }} / E_{\mathrm{DHW}}\right)$ and volumes ( $\left.V_{\text {unsup }} / V_{\mathrm{DHW}}\right)$, volumes of withdrawn DHW at a temperature between 45 and $43{ }^{\circ} \mathrm{C}\left(V_{T 45-43}\right), 43$ to $40{ }^{\circ} \mathrm{C}\left(V_{T 43-40}\right)$, below $40{ }^{\circ} \mathrm{C}\left(V_{T<40}\right)$ and minimum temperature $\left(T_{\text {DHWmin }}\right)$ reached during the simulation for each of the profiles RDP2, EU2mod, BRE1mod, EN 12977, 1 draw-off and 1 draw-off0.

This analysis focuses primarily on the ratios of unsupplied volume and energy and the minimum temperature because the other parameters are to a certain degree already involved in these parameters. The comparison of the pertinent values of 
Table 5

Comparison of different profiles RDP2, EU2mod, BRE1mod, EN 12977, 1 draw-off and 1 draw-off0 when a thermostatic mixing-valve is employed

\begin{tabular}{llcclclllll}
\hline Profile & $\begin{array}{l}V_{\text {DHW }} \\
(1)\end{array}$ & $\begin{array}{l}V_{\text {unsup }} \\
(1)\end{array}$ & $\begin{array}{l}V_{\text {unsup }} / V_{\text {DHW }} \\
(\%)\end{array}$ & $\begin{array}{l}V_{T 45-43} \\
(1)\end{array}$ & $\begin{array}{l}V_{T 43-40} \\
(1)\end{array}$ & $\begin{array}{l}V_{T<40} \\
(1)\end{array}$ & $\begin{array}{l}T_{\text {DHW, min }} \\
\left({ }^{\circ} \mathrm{C}\right)\end{array}$ & $\begin{array}{l}E_{\mathrm{DHW}} \\
(\mathrm{kWh})\end{array}$ & $\begin{array}{l}E_{\text {unsup }} \\
(\mathrm{kWh})\end{array}$ & $\begin{array}{l}E_{\text {unsup }} / E_{\mathrm{DHW}} \\
(\%)\end{array}$ \\
\hline RDP2 & 180 & 0 & 0.0 & 0.0 & 0.0 & 0.0 & 45.0 & 7.333 & 0.000 & 0.00 \\
EU2mod & 180 & 24 & 13.4 & 8.4 & 14.4 & 1.2 & 39.9 & 7.264 & 0.069 & 0.95 \\
BRE1mod & 180 & 19.3 & 10.7 & 2.7 & 11.3 & 5.3 & 39.1 & 7.294 & 0.039 & 0.53 \\
EN12977 & 180 & 22 & 12.2 & 6.7 & 13.3 & 2.0 & 39.6 & 7.275 & 0.027 & 0.79 \\
1 Draw-off & 180 & 20 & 11.1 & 6.7 & 12.7 & 0.7 & 40.0 & 7.285 & 0.048 & 0.66 \\
1 Draw-off0 & 180 & 2 & 1.1 & 2.0 & 0.0 & 0.0 & 44.5 & 7.332 & 0.001 & 0.01 \\
\hline
\end{tabular}

Compared parameters. Withdrawn volume ( $\left.V_{\mathrm{DHW}}\right)$, energy DHW ( $\left.E_{\mathrm{DHW}}\right)$, “unsupplied" energy to DHW below a temperature level of $45^{\circ} \mathrm{C}\left(E_{\mathrm{unsup}}\right)$, total volume of DHW below $45^{\circ} \mathrm{C}\left(V_{\text {unsup }}\right)$, volume of DHW at temperatures from 45 to $43^{\circ} \mathrm{C}\left(V_{T 45-43}\right)$, volume of DHW at temperatures from 43 to $40^{\circ} \mathrm{C}\left(V_{T 43-40}\right)$, volume of DHW at temperatures below $40{ }^{\circ} \mathrm{C}\left(V_{T}<40\right)$, minimum temperature reached during the simulation $\left(T_{\mathrm{DHW} m i n}\right)$, ratios of unsupplied and supplied energy $\left(E_{\text {unsup }} / E_{\mathrm{DHW}}\right)$ and volume $\left(V_{\text {unsup }} / V_{\mathrm{DHW}}\right)$. 
the the ratio ( $V_{\text {unsup }} / V_{\text {DHW }}$ ) shows that the RDP2 profile always provides DHW at the required temperature of $45^{\circ} \mathrm{C}$, whereas the other profiles fail to do so to a varying degree. The ratio ( $V_{\text {unsup }} / V_{\text {DHW }}$ ) varies from $11.1 \%$ for a single draw-off to zero for RDP2. A decreasing trend of the ratio corresponds to the increasing number of draw-offs in the profiles. However, the values of ( $V_{\text {unsup }} / V_{\text {DHW }}$ ) for EU2mod at $13.3 \%$ and single draw-offo at $1.1 \%$ do not comply with this trend. The reason for the EU2mod "high" unsupplied volume-ratio can be explained by a prolonged, high flow-rate draw-off (i.e., an evening shower of 46.51 ) at the end of the profile, when the store is at a relatively low temperature. The large difference of the ratio ( $V_{\text {unsup }} /$ $\left.V_{\text {DHW }}\right)$ between the single draw-off and single draw-off0 profile of $10 \%$ demonstrates that the time of occurrence affects the performance of the store. The choice of profile accounts for a difference of up to $13.3 \%$ in the unsupplied volume-ratio.

The unsupplied energy-ratio $\left(E_{\mathrm{unsup}} / E_{\mathrm{DHW}}\right)$ follows a similar trend as described above, with a maximum difference between profiles of $0.95 \%$.

In Table 5, the volumes of water below $45^{\circ} \mathrm{C}$ for the three specified temperature ranges are also listed. These data give a more detailed picture of the degree of under-performance. The minimum achieved-temperature $\left(T_{\mathrm{DHWmin}}\right)$ is listed for each profile and shows that the RDP2 always attained the required temperature of $45^{\circ} \mathrm{C}$, whereas for all other profiles, the minimum temperature was approximately $40^{\circ} \mathrm{C}$. However, the single draw-off0 profile achieved $T_{\text {DHWin }}=44.5^{\circ} \mathrm{C}$ due to the whole volume of the DHW being withdrawn from a fully-charged store at temperature $80{ }^{\circ} \mathrm{C}$.

Overall, the results indicate that three profile-parameters have a direct impact on the performance of the store. A larger number of small draw-offs in the profile for a constant daily draw-off results in a better storage performance. Substantial draw-offs occurring later in the day decrease the performance due to the lower store temperature. The length and flow rate of individual draw-offs also affect the performance.

\subsection{Analysis of the system's behaviour without a thermostatic mixing-valve}

These simulation results, for the same parameters as in the previous analysis, are shown in Table 6. The comparison of the unsupplied-volume ratios follows the previously mentioned pattern and confirms the conclusion that a higher number drawoffs significantly decreases the unsupplied-water-volume ratio. The maximum difference of unsupplied-water-volume ratio between the RDP2 and the single draw-off pattern is $11.6 \%$. The effect of the time of occurrence of the draw-off can be significant; the difference in unsupplied-volume ratio between a single draw-off at noon and at the beginning of the day is $5.5 \%$.

Comparison of the unsupplied-energy ratio follows the same trend as the volume ratio and the maximum difference between the RDP2 and the EN12977 patterns is 3.5\%.

The minimum hot-water temperature recorded for the BRE1mod profile is low at $29.3{ }^{\circ} \mathrm{C}$, which is caused by two long draw-offs at the end of the profile. RDP2 again shows the least fall in the required temperature, with $T_{\mathrm{DHWmin}}=34.2^{\circ} \mathrm{C}$.

As there is no thermostatic mixing-valve, an evaluation of the energy content of the equivalent volume has been made, i.e., how much energy can be withdrawn from the thermal store? For comparison, the expended energy can be indicated by the 
Table 6

Comparison of behaviours for profiles RDP2, EU2mod, BRE1mod, EN 12977, 1 draw-off and 1 draw-off0 for the system without a thermostatic mixing-valve

\begin{tabular}{llllccccccc}
\hline Profile & $\begin{array}{l}V_{\text {DHW }} \\
(1)\end{array}$ & $\begin{array}{l}V_{\text {unsup }} \\
(1)\end{array}$ & $\begin{array}{l}V_{\text {unsup }} / V_{\text {DHW }} \\
(\%)\end{array}$ & $\begin{array}{l}V_{T 45-43} \\
(1)\end{array}$ & $\begin{array}{l}V_{T 43-40} \\
(1)\end{array}$ & $\begin{array}{l}V_{T<40} \\
(1)\end{array}$ & $\begin{array}{l}T_{\text {DHW,min }} \\
\left({ }^{\circ} \mathrm{C}\right)\end{array}$ & $\begin{array}{l}E_{\mathrm{DHW}} \\
(\mathrm{kWh})\end{array}$ & $\begin{array}{l}E_{\text {unsup }} \\
(\mathrm{kWh})\end{array}$ & $\begin{array}{l}E_{\text {unsup }} / E_{\mathrm{DHW}} \\
(\%)\end{array}$ \\
\hline RDP2 & 180 & 54.0 & 30.0 & 4.0 & 9.0 & 41.0 & 34.2 & 9.849 & 0.437 & 4.4 \\
EU2mod & 180 & 56.8 & 31.5 & 13.6 & 3.6 & 39.6 & 30.0 & 9.614 & 0.570 & 5.9 \\
BRE1mod & 180 & 66.7 & 36.9 & 6.0 & 4.0 & 56.7 & 29.3 & 9.410 & 0.694 & 7.4 \\
EN12977 & 180 & 67.5 & 37.5 & 5.0 & 5.0 & 57.5 & 30.0 & 9.090 & 0.723 & 8.0 \\
1 Draw-off & 180 & 75.0 & 41.7 & 10.0 & 12.5 & 52.5 & 30.7 & 8.932 & 0.682 & 7.6 \\
1 Draw-off0 & 180 & 65.0 & 36.1 & 7.5 & 12.5 & 45.0 & 31.8 & 9.413 & 0.557 & 5.9 \\
\hline
\end{tabular}

Parameters. Withdrawn volume ( $\left.V_{\mathrm{DHW}}\right)$, energy in the DHW $\left(E_{\mathrm{DHW}}\right)$, unsupplied energy to DHW below the temperature level of $45^{\circ} \mathrm{C}\left(E_{\text {unsup }}\right)$, total volume of DHW at below $45^{\circ} \mathrm{C}\left(V_{\text {unsup }}\right)$, volume of DHW at temperatures from 45 to $43{ }^{\circ} \mathrm{C}\left(V_{T 45-43}\right)$, volume of DHW at temperatures from 43 to $40{ }^{\circ} \mathrm{C}\left(V_{T 43-40}\right)$, volume of DHW at temperatures below $40{ }^{\circ} \mathrm{C}\left(V_{T<40}\right)$, the minimum temperature $\left(T_{\mathrm{DHW} \text { min }}\right)$ reached during the simulation as well as ratios of "unsupplied" and "supplied" energies $\left(E_{\mathrm{unsup}} / E_{\mathrm{DHW}}\right)$ and volumes ( $\left.V_{\text {unsup }} / V_{\mathrm{DHW}}\right)$. 


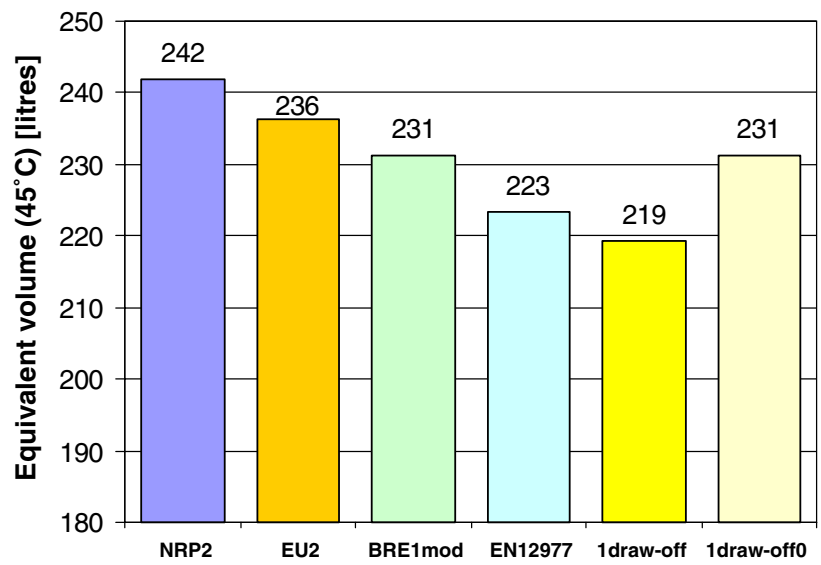

Fig. 11. Comparison of different profiles namely RDP2, EU2mod, BRE1mod, EN 12977, 1 draw-off and 1 draw-off0 equivalent volume ( $V_{\text {equi }}$ ) of withdrawn hot-water, without thermostatic mixing-valve for hotwater delivered at $45^{\circ} \mathrm{C}$.

equivalent volume of DHW at a temperature of $45^{\circ} \mathrm{C}$. Results show that, even though the store volume is the same, different equivalent volumes of hot water at $T_{\text {equi }}=45^{\circ} \mathrm{C}$ will be withdrawn to satisfy the different profiles.

In Fig. 11, the equivalent volume ( $V_{\text {equi }}$ ) for each profile is shown. RDP2 has the highest equivalent volume of 2421 , whereas the single draw-off profile manages only 2191 . The difference can be ascribed to the number of draw-offs for the profile and the times of withdrawal. The single draw-off 0 has an equivalent volume of $2311 \mathrm{compared}$ with 2191 for single draw-off, which occurs later, i.e., at noon. The maximum equivalent volume difference between the RDP2 and the single draw-off is $9 \%$.

It can be concluded from the results of these simulations that the store's performance is affected by the number of draw-offs in the profile: long draw-offs do not provide as much energy from a thermal store as several shorter draw-offs and the time of day of the occurrence of the draw-off is also an important factor.

\section{Summary and conclusions}

- The simulations carried out demonstrated that the TRNSYS model of the stratified store type 60 is not able to predict accurately the behaviour of a store with an immersed DHW HX for short draw-offs.

- An enhanced dynamic model NEM for an immersed HX was developed and validated against measured data. The enhanced dynamic model NEM takes into account the volume of the HX and the temperature-recovery processes for the HX after a draw-off.

- A need was identified for a realistic DHW daily-profile for testing and simulation of thermal stores.

- Three realistic daily profiles, based on field measurements, were developed namely RDP1 “light” 100 1, RDP2 "medium” 180 1; and RDP3 "heavy" 3201. 
- A methodology for the comparison of different DHW draw-off profiles has been developed, based on parameters such as the ratios of unsupplied volume or energy, proportions of volumes at lower temperatures than required, minimum temperature experienced and the equivalent volume.

- The comparison proved that significant differences in behaviour exist between profiles RDP2, EU2mod, BRE1mod, EN 12977, single draw-off and single draw-offo.

- The comparison found that three parameters significantly affected the store's performance - the number of draw-offs, late (in the day) long draw-offs with high flow-rates and the time of a shower and bath draw-offs. The differences are significant; store performance being 13.3\% higher for the RDP 2 profile than for the traditional single draw-off testing DHW profile.

- The immersed heat-exchanger coil should be located in the upper region of the hot-water tank, so as to achieve high heat-extraction rates from the tank water.

\section{Appendix}

Developed realistic daily profiles (RDPs) are given in Table 7-9.

Table 7

Realistic daily-profile RDP1 for a withdrawn water volume of 100 l: type, volume, flow rate, energy and times of occurrences of draw-offs during the day

\begin{tabular}{lllrcl}
\hline Number of withdrawal & Time $(\mathrm{hh}: \mathrm{mm})$ & Energy $(\mathrm{kWh})$ & Flow rate $(\mathrm{kg} / \mathrm{h})$ & Volume $(\mathrm{l})$ & Type of load \\
\hline 1 & $05: 00$ & 0.041 & 60 & 1 & Short \\
2 & $05: 15$ & 0.244 & 360 & 6 & Medium \\
3 & $06: 00$ & 0.041 & 60 & 1 & Short \\
4 & $07: 00$ & 1.628 & 480 & 40 & Shower \\
5 & $08: 00$ & 0.041 & 60 & 1 & Short \\
6 & $08: 15$ & 0.244 & 360 & 6 & Medium \\
7 & $09: 00$ & 0.041 & 60 & 1 & Short \\
8 & $10: 00$ & 0.041 & 60 & 1 & Short \\
9 & $11: 00$ & 0.041 & 60 & 1 & Short \\
10 & $11: 15$ & 0.244 & 360 & 6 & Medium \\
11 & $12: 00$ & 0.041 & 60 & 1 & Short \\
12 & $13: 00$ & 0.041 & 60 & 1 & Short \\
13 & $14: 00$ & 0.041 & 60 & 1 & Short \\
14 & $14: 15$ & 0.244 & 360 & 6 & Medium \\
15 & $15: 00$ & 0.041 & 60 & 1 & Short \\
16 & $16: 00$ & 0.041 & 60 & 1 & Short \\
17 & $17: 00$ & 0.041 & 60 & 1 & Short \\
18 & $17: 15$ & 0.244 & 360 & 6 & Medium \\
19 & $18: 00$ & 0.041 & 60 & 1 & Short \\
20 & $19: 00$ & 0.041 & 60 & 1 & Short \\
21 & $20: 00$ & 0.041 & 60 & 1 & Short \\
22 & $20: 15$ & 0.244 & 360 & 6 & Medium \\
23 & $21: 00$ & 0.041 & 60 & 1 & Short \\
24 & $22: 00$ & 0.041 & 60 & 1 & Short \\
25 & $22: 50$ & 0.244 & 360 & 6 & Medium \\
26 & $23: 00$ & 0.041 & 60 & 1 & Short \\
& & & & & \\
Total & & 4.03 & & & \\
\hline & & & & 100 & \\
\hline
\end{tabular}


Table 8

Realistic daily-profile RDP2, for a withdrawn water volume of 180 1: type, volume, flow rate, energy and times of occurrences of draw-offs during the day

\begin{tabular}{|c|c|c|c|c|c|}
\hline Number of withdrawal & Time (hh:mm) & Energy $(\mathrm{kWh})$ & Flow rate $(\mathrm{kg} / \mathrm{h})$ & Volume (1) & Type of load \\
\hline 1 & 05:00 & 0.041 & 60 & 1 & Short \\
\hline 2 & $05: 40$ & 0.041 & 60 & 1 & Short \\
\hline 3 & $05: 45$ & 0.244 & 360 & 6 & Medium \\
\hline 4 & $06: 20$ & 0.041 & 60 & 1 & Short \\
\hline 5 & $06: 55$ & 0.041 & 60 & 1 & Short \\
\hline 6 & 07:00 & 1.628 & 480 & 40 & Shower \\
\hline 7 & $07: 15$ & 0.244 & 360 & 6 & Medium \\
\hline 8 & $07: 40$ & 0.041 & 60 & 1 & Short \\
\hline 9 & $08: 20$ & 0.041 & 60 & 1 & Short \\
\hline 10 & $08: 45$ & 0.244 & 360 & 6 & Medium \\
\hline 11 & 09:00 & 0.041 & 60 & 1 & Short \\
\hline 12 & 09:40 & 0.041 & 60 & 1 & Short \\
\hline 13 & $10: 15$ & 0.244 & 360 & 6 & Medium \\
\hline 14 & $10: 20$ & 0.041 & 60 & 1 & Short \\
\hline 15 & $11: 00$ & 0.041 & 60 & 1 & Short \\
\hline 16 & $11: 40$ & 0.041 & 60 & 1 & Short \\
\hline 17 & $11: 45$ & 0.244 & 360 & 6 & Medium \\
\hline 18 & $12: 20$ & 0.041 & 60 & 1 & Short \\
\hline 19 & $13: 00$ & 0.041 & 60 & 1 & Short \\
\hline 20 & $13: 15$ & 0.244 & 360 & 6 & Medium \\
\hline 21 & $13: 40$ & 0.041 & 60 & 1 & Short \\
\hline 22 & $14: 20$ & 0.041 & 60 & 1 & Short \\
\hline 23 & $14: 45$ & 0.244 & 360 & 6 & Medium \\
\hline 24 & $15: 00$ & 0.041 & 60 & 1 & Short \\
\hline 25 & $15: 40$ & 0.041 & 60 & 1 & Short \\
\hline 26 & $16: 15$ & 0.244 & 360 & 6 & Medium \\
\hline 27 & $16: 20$ & 0.041 & 60 & 1 & Short \\
\hline 28 & $17: 00$ & 0.041 & 60 & 1 & Short \\
\hline 29 & $17: 40$ & 0.041 & 60 & 1 & Short \\
\hline 30 & $17: 45$ & 0.244 & 360 & 6 & Medium \\
\hline 31 & $18: 20$ & 0.041 & 60 & 1 & Short \\
\hline 32 & $19: 00$ & 0.041 & 60 & 1 & Short \\
\hline 33 & $19: 15$ & 0.244 & 360 & 6 & Medium \\
\hline 34 & $19: 30$ & 1.628 & 480 & 40 & Shower \\
\hline 35 & $19: 40$ & 0.041 & 60 & 1 & Short \\
\hline 36 & $20: 20$ & 0.041 & 60 & 1 & Short \\
\hline 37 & $20: 45$ & 0.244 & 360 & 6 & Medium \\
\hline 38 & $21: 00$ & 0.041 & 60 & 1 & Short \\
\hline 39 & $21: 40$ & 0.041 & 60 & 1 & Short \\
\hline 40 & $22: 15$ & 0.244 & 360 & 6 & Medium \\
\hline 41 & $22: 20$ & 0.041 & 60 & 1 & Short \\
\hline 42 & 23:00 & 0.041 & 60 & 1 & Short \\
\hline Total & & 7.33 & & 180 & \\
\hline
\end{tabular}


Table 9

Realistic daily-profile RDP3, for a withdrawn water volume of 320 1: type, volume, flow rate, energy and times of occurrences of draw-offs during the day

\begin{tabular}{|c|c|c|c|c|c|}
\hline Number of withdrawal & Time (hh:mm) & Energy (kWh) & Flow rate $(\mathrm{kg} / \mathrm{h})$ & Volume (1) & Type of load \\
\hline 1 & 05:00 & 0.041 & 60 & 1 & Short \\
\hline 2 & $05: 40$ & 0.041 & 60 & 1 & Short \\
\hline 3 & $05: 45$ & 0.244 & 360 & 6 & Medium \\
\hline 4 & $06: 20$ & 0.041 & 60 & 1 & Short \\
\hline 5 & $06: 55$ & 0.041 & 60 & 1 & Short \\
\hline 6 & 07:00 & 1.628 & 480 & 40 & Shower \\
\hline 7 & $07: 15$ & 0.244 & 360 & 6 & Medium \\
\hline 8 & $07: 30$ & 1.628 & 480 & 40 & Shower \\
\hline 9 & $07: 40$ & 0.041 & 60 & 1 & Short \\
\hline 10 & 08:20 & 0.041 & 60 & 1 & Short \\
\hline 11 & $08: 45$ & 0.244 & 360 & 6 & Medium \\
\hline 12 & 09:00 & 0.041 & 60 & 1 & Short \\
\hline 13 & 09:40 & 0.041 & 60 & 1 & Short \\
\hline 14 & $10: 15$ & 0.244 & 360 & 6 & Medium \\
\hline 15 & $10: 20$ & 0.041 & 60 & 1 & Short \\
\hline 16 & 11:00 & 0.041 & 60 & 1 & Short \\
\hline 17 & $11: 40$ & 0.041 & 60 & 1 & Short \\
\hline 18 & $11: 45$ & 0.244 & 360 & 6 & Medium \\
\hline 19 & $12: 20$ & 0.041 & 60 & 1 & Short \\
\hline 20 & $13: 00$ & 0.041 & 60 & 1 & Short \\
\hline 21 & $13: 15$ & 0.244 & 360 & 6 & Medium \\
\hline 22 & $13: 40$ & 0.041 & 60 & 1 & Short \\
\hline 23 & $14: 20$ & 0.041 & 60 & 1 & Short \\
\hline 24 & $14: 45$ & 0.244 & 360 & 6 & Medium \\
\hline 25 & $15: 00$ & 0.041 & 60 & 1 & Short \\
\hline 26 & $15: 40$ & 0.041 & 60 & 1 & Short \\
\hline 27 & $16: 15$ & 0.244 & 360 & 6 & Medium \\
\hline 28 & $16: 20$ & 0.041 & 60 & 1 & Short \\
\hline 29 & $17: 00$ & 0.041 & 60 & 1 & Short \\
\hline 30 & $17: 40$ & 0.041 & 60 & 1 & Short \\
\hline 31 & $17: 45$ & 0.244 & 360 & 6 & Medium \\
\hline 32 & $18: 20$ & 0.041 & 60 & 1 & Short \\
\hline 33 & $19: 00$ & 0.570 & 840 & 140 & Bath \\
\hline 34 & 19:09 & 0.041 & 60 & 1 & Short \\
\hline 35 & $19: 15$ & 0.244 & 360 & 6 & Medium \\
\hline 36 & $19: 40$ & 0.041 & 60 & 1 & Short \\
\hline 37 & $20: 20$ & 0.041 & 60 & 1 & Short \\
\hline 38 & $20: 45$ & 0.244 & 360 & 6 & Medium \\
\hline 39 & 21:00 & 0.041 & 60 & 1 & Short \\
\hline 40 & $21: 40$ & 0.041 & 60 & 1 & Short \\
\hline 41 & $22: 15$ & 0.244 & 360 & 6 & Medium \\
\hline 42 & $22: 20$ & 0.041 & 60 & 1 & Short \\
\hline 43 & 23:00 & 0.041 & 60 & 1 & Short \\
\hline Total & & 7.86 & & 320 & \\
\hline
\end{tabular}




\section{References}

[1] ANSI/ASHRAE Standard 124-1991, Method of testing for rating combination space heating/water heating appliances. ASHRAE; 1991.

[2] EN 12977-2. Thermal-solar systems and components: custom-built systems, test methods. Brussels: CEN; 2001.

[3] prEN 13203. Qualification of hot-water functions of gas - fired appliances for domestic use. Brussels: European Committee for Standardization; 1998.

[4] Klein SA, Beckman WA, Mitchell JW, Duffie JA, Duffie NA, Freeman TL. TRNSYS 15a transient simulation and program. Madison: Solar Energy Laboratory, University of Wisconsin; 2000.

[5] Holman JP. Heat transfer. 6th ed. New York: McGraw-Hill; 1986.

[6] Experimental measurements taken in a laboratory carried out by Enplan; 2002.

[7] Jordan U, Vajen K. Realistic domestic hot-water profiles in different time scales. IEA SHC Task 26: Solar Combisystems 2001.

[8] Mandate to CEN and CENELEC for the elaboration and adoption of measurement standards for household appliances: water-heaters, hot-water storage appliances and water-heating systems. Brussels: European Commission; 2002.

[9] Loose P. Der Tagesgang des Trink-Warmwasser-Bedarfes, HLH 42, No. 2; 1991.

[10] Nipkow J. Warmwasser-Zapfungsverhalten. Schlussbericht. Industrielle Betriebe der Stadt Zürich: Zürich; 1999.

[11] Real M, Nipkow J, Tanner L, Stadelmann B, Dinkel F. Simulation Warmwassersysteme. Schullssbericht forschungprogrammm Wasser. Eidgenössische Drucksachen- und Materialzentrale Bern 1999.

[12] Dichter E. Dusch-and Badeverhalsten. Bericht zu einer Repräsentativumfrage, Eidgenössische Drucksachen- und Materialzentrale. Bern; 1999.

[13] Jordan U, Vajen K. Influence of the DHW-load profile on the fractional energy savings: a case study of a solar combi-system with TRNSYS simulations. Sol Energy 2001;69(6):197-208.

[14] Analysis of energy efficiency of domestic electric-storage water heaters, 1998 Contract No. Save-4 1031/E/95-013; 1998.

[15] DIN 4708 Zentrale Brauchwasser-Erwärmungsanlagen; Begriffe und Berechnungsgrundlagen; 1994.

\section{Glossary}

DHW profile: Plot of rate of delivery of hot water versus time, so that the area under the profile provides an indication of the total volume delivered - see Fig. 1. 